\title{
Joint Toxicity of Zinc, Cadmium and Plumbum on S.obliquus
}

\author{
Fan Zhang ${ }^{1, a}$, Xin Zhang ${ }^{1, a}$, Nan Xiao ${ }^{1, a}$, Minyi Zheng ${ }^{1, a}$, Litang Qin²,a ${ }^{2}$ Lingyun \\ $\mathrm{Mo}^{2, \mathrm{a} *}$
}

${ }^{1}$ College of Environmental and Engineering, Guilin University of Technology, Guilin 541004, China

${ }^{2}$ Guangxi Key Laboratory of Environmental Pollution Control Theory and Technology, Guilin

University of Technology, Guilin 541004, China

aEmail: meizictgu@163.com

Keywords: Heavy metal; S.obliquus; Mixture toxicity; The mixture experimental design.

Abstract. In this article, the study assessed $\mathrm{ZnSO}_{4} \cdot 7 \mathrm{H}_{2} \mathrm{O}[\mathrm{Zn}], \mathrm{Pb}\left(\mathrm{NO}_{3}\right)_{2}[\mathrm{~Pb}], \mathrm{CdCl}_{2} \cdot 2.5 \mathrm{H}_{2} \mathrm{O}[\mathrm{Cd}]$, and set the S.obliquus as biological indicators to study the toxicity of binary mixtures after $96 \mathrm{~h}$ by trace analysis methods. The results showed that the relationship of toxicity among these compounds as follows: $\mathrm{Cd}>\mathrm{Zn}>\mathrm{Pb}$. In addition, $\mathrm{Zn}, \mathrm{Pb}$ and $\mathrm{Cd}$ experienced interactions with each other, which mainly showed additive effects and synergy effects. And with the changes of concentration, the types of the effect are also changed accordingly.

\section{Introduction}

The situation of soil heavy metal contamination in China is grim now, which is mainly caused by the pollution of $\mathrm{Hg}, \mathrm{Cd}, \mathrm{Pb}, \mathrm{As}, \mathrm{Zn}$ and $\mathrm{Cu}$. Heavy metal pollutants can not be degraded by chemical or biological methods, and are easy to accumulate inside plants, animals and even human beings through the food chain cycle, resulting in the growth of toxicity, which threats the ecological environment, food safety and human health ${ }^{[1-3]}$. In recent years, heavy metal contamination of soil is serious, not only influenced the quality of agricultural products, but also disrupted the arable land.

Alga is a kind of primary producer in aquatic ecosystems, and it can be an indicator water quality ${ }^{[4]}$. S.obliquus is a freshwater unicellular chlorella, widely distributed in the river area. It has strong vitality, and breed quickly. Also, it is sensitive to the changes of environmental conditions, when the impact on the water environment of the detection of pollutants, usually the impact of pollutants on S.obliquus as an important indicator test. In this study, S.obliquus as indicator organisms, Acute toxicity analysis of heavy metals $\mathrm{Zn}, \mathrm{Pb}, \mathrm{Cd}$ single and binary mixtures on S.Obliquus. In order to more accurately assess the ecological risk of contamination.

\section{Material and methods}

\section{Experimental materials}

The freshwater microalgae used was S.obliquus FACHB-12, which was supplied by Freshwater Algae Culture Collection at the Institute of Hydrobiology, FACHB, upon receipt of algae, in a clean workbench, algae will be transferred to the prepared culture media, S.obliquus culture medium using BG11. The Tecan M200 PRO purchased from TECAN Switzerland company, 96-well 
flat-bottomed microplate purchased from greiner company. The properties of three heavy metals, $\mathrm{ZnSO}_{4} \cdot 7 \mathrm{H}_{2} \mathrm{O}[\mathrm{Zn}], \mathrm{AR}, \mathrm{CdCl}_{2} \cdot 2.5 \mathrm{H}_{2} \mathrm{O}[\mathrm{Cd}], \mathrm{RG}$ and $\mathrm{Pb}\left(\mathrm{NO}_{3}\right)_{2}[\mathrm{~Pb}], \mathrm{RG}$, used in the test are listed in table 1 . All of them were prepared in distilled water and stored at $4^{\circ} \mathrm{C}$.

Table 1. Chemical properties of three heavy metals

\begin{tabular}{cccc}
\hline Compound & CAS & MW & $\begin{array}{c}\text { Purity/ } \\
\%\end{array}$ \\
\hline $\mathrm{ZnSO}_{4} \cdot 7 \mathrm{H}_{2} \mathrm{O}$ & $7446-20-0$ & 287.58 & $\geq 99.5$ \\
$\left.\mathrm{~Pb} \mathrm{NO}_{3}\right)_{2}$ & $10099-74-8$ & 331.21 & 99 \\
$\mathrm{CdCl}_{2} \cdot 2.5 \mathrm{H}_{2}$ & $7790-78-5$ & 228.36 & 98 \\
$\mathrm{O}$ & & & \\
\hline
\end{tabular}

\section{Experimental Methods}

\section{The cultivation of S.obliquus}

In a clean bench sterile inoculation algae and then placed in artificial light incubator thermostat cultured, set the temperature $22^{\circ} \mathrm{C}$, light intensity about 3000lux, light-dark cycle of $12 \mathrm{~h}$ : $12 \mathrm{~h}$. Algae cell metabolism in the most productive period of inoculation, before the toxicity test, the adapter in the logarithmic phase of algae to fresh culture medium, culture is carried out after the experiment $2 \mathrm{~d}$.

\section{Toxicity Test}

Before the start of the experiment, when the test algae by microplate absorbance greater than 0.24 , Referring to conduct experiments Chlorella microplate toxicity analysis (MTA) ${ }^{[5]}$, the experiment was repeated 3 times per plate. Microplate after adding transparent cover at a temperature of $22^{\circ} \mathrm{C}$, illumination 3000lux, Light - dark cycle than $12 \mathrm{~h}: 12 \mathrm{~h}$. measured exposure time $\mathrm{t}=0,24,48,72$ and $96 \mathrm{~h}$ microplate by Microplate reader, and the wavelength was $682 \mathrm{~nm}$. The toxicity of a treatment was expressed as a percentage inhibition of the cell growth showed as Eq. 1.

$$
I=1-\left(O D_{\mathrm{tit}}-O D_{t, 0}\right)\left(O D_{0, i}-O D_{00}\right)
$$

Where $E$ was the inhibition at a time, $i$ was expose time, $O D_{t, i}$ was measured optical density of treated cells at time $i, O D_{t, 0}$ was measured optical density of treated cells at time $0, O D_{0, i}$ was measured optical density of controlled cells at time $i, O D_{0,0}$ was measured optical density of controlled cells at time 0 .

\section{The mixture experimental design}

Binary mixtures used is Equivalent-Effect concentration Ratio (EECR) ${ }^{[6]}$, to explore the mixed heavy metal toxicity. In this paper, we have a total of three sets of $\mathrm{Zn}-\mathrm{Pb}, \mathrm{Zn}-\mathrm{Cd}, \mathrm{Pb}-\mathrm{Cd}$ binary mixtures, using the Mix-EC20, Mix-50, Mix-NOEC mixed system, for mixture toxicity testing and analysis.

\section{Combination Index}

Combination Index ${ }^{[7]}$ calculated as follows Eq. 2:

$C I_{\mathrm{N}}=\sum_{\mathrm{i}=1}^{\mathrm{n}} \frac{\epsilon_{\mathrm{i}}}{E C_{S_{j}}}$

In the formula, $\mathrm{CI}_{\mathrm{x}}$ is the $\mathrm{Cl}$ value when the effect is $\mathrm{x} \%$; $\mathrm{Ci}$ is the concentration of the $\mathrm{i}$-th compound mixture which producted the effect of $\mathrm{x} \%$; ECx, $\mathrm{i}$ is the concentration of the $\mathrm{i}$-th compound mixture which alone producted the effect of $x \% ; n$ is the mixture fraction.

$\mathrm{CI}=1,>1<1$, said mixture interaction were additive, antagonistic and synergistic effect, this paper introduces observations based on the $95 \%$ confidence interval, if the confidence limit is 
greater than 1, at the same time, the lower confidence limit of less than 1 , the mixture interaction is added.

\section{Results and disscussion}

\section{The toxicity of single heavy metal compounds on S.obliquus}

Three kinds of heavy metals on S.obliquus 96h Toxic effects can be fitted with a Logit or Weibull function, showed in table 2. Three compounds CRC fitting parameters R>0.95 and RMSE $<0.08$. The toxicity of a single compound is: $\mathrm{Cd}>\mathrm{Zn}>\mathrm{Pb}$. The $96 \mathrm{~h}$ concentration-response curves of three heavy metals on S.obliquus were showed in Fig.1.

Table 2. The 96h statistics of toxicity of single heavy metals on S.obliquus

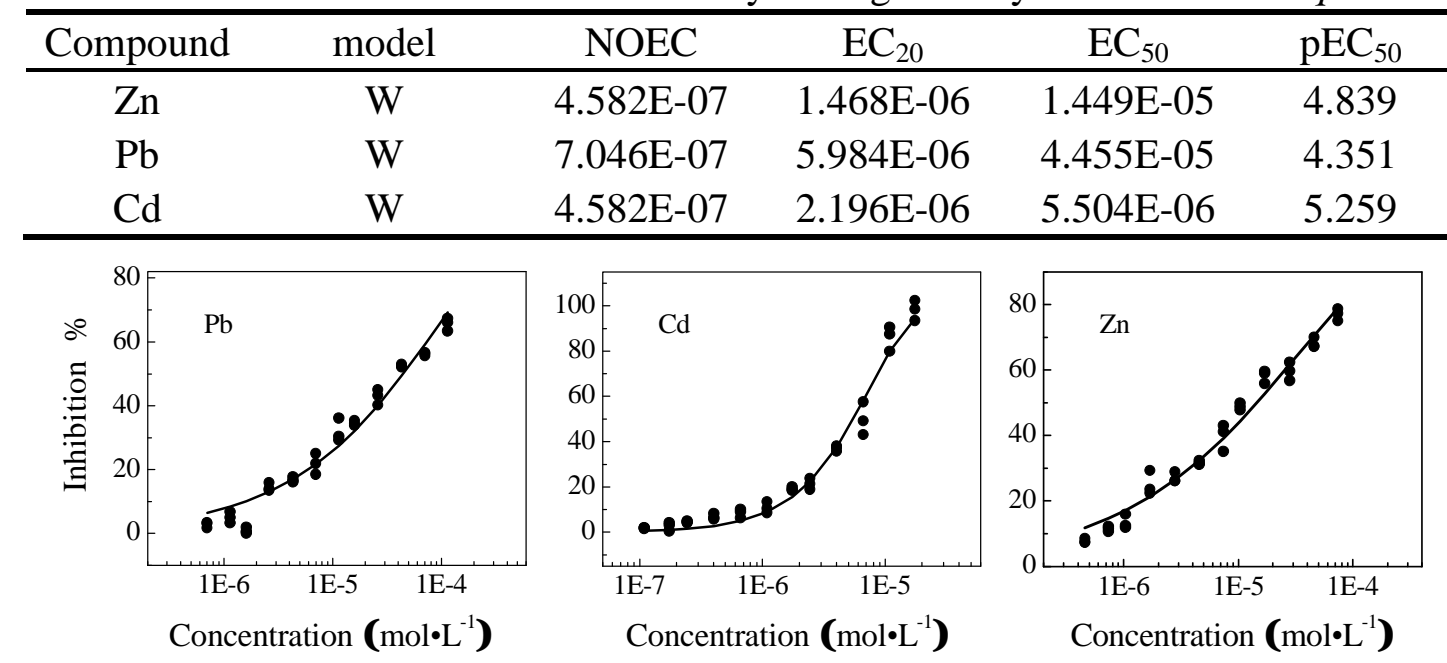

Fig.1 The 96h concentration-response curves of $\mathrm{Zn}, \mathrm{Cd}$ and $\mathrm{Pb}$ on S.obliquus

\section{The toxicity of binary mixture on S.obliquus}

$\mathrm{Zn}, \mathrm{Pb}, \mathrm{Cd}$ three compounds build three binary mixed system, using Equivalent-Effect concentration Ratio design 3-ray binary mixtures for each system: Mix-EC20、Mix-50、Mix-NOEC. All data can be fitted with a Logit or Weibull function, each of rays obtained fitting parameters $\alpha, \beta$, $\mathrm{R}, \mathrm{RMSE}$ and $\mathrm{pEC}_{50}$ are in Table 3. The response-Index curves of $\mathrm{Pb}-\mathrm{Cd}, \mathrm{Zn}-\mathrm{Cd}$ and $\mathrm{Zn}-\mathrm{Pb}$ were showed in Fig.2, Fig.3 and Fig.4, respectively.

Table 3. The 96h statistics of toxicity of binary mixture heavy metals on S.obliquus

\begin{tabular}{|c|c|c|c|c|c|c|c|c|c|}
\hline $\begin{array}{l}\text { Binary } \\
\text { system }\end{array}$ & Component & & & model & $\alpha$ & $\beta$ & $R^{2}$ & $R M S E$ & $\mathrm{pEC}_{50}$ \\
\hline \multirow{4}{*}{$\mathrm{Pb}-\mathrm{Cd}$} & & $\mathrm{Pb}$ & $\mathrm{Cd}$ & & & & & & \\
\hline & EE-20 & 0.7315 & 0.2685 & W & 4.700 & 1.090 & 0.9619 & 0.0368 & 4.669 \\
\hline & EE-50 & 0.8900 & 0.1100 & $\mathrm{~L}$ & 8.590 & 1.960 & 0.9481 & 0.0599 & 4.383 \\
\hline & EE-NOEC & 0.6361 & 0.3639 & $\mathrm{~L}$ & 12.790 & 2.500 & 0.9898 & 0.0188 & 5.116 \\
\hline \multirow{4}{*}{$\mathrm{Zn}-\mathrm{Cd}$} & & $\mathrm{Zn}$ & $\mathrm{Cd}$ & & & & & & \\
\hline & EE-20 & 0.4007 & 0.5993 & $\mathrm{~L}$ & 18.340 & 3.700 & 0.9620 & 0.0528 & 4.957 \\
\hline & EE-50 & 0.7247 & 0.2753 & $\mathrm{~L}$ & 13.550 & 2.890 & 0.9750 & 0.04247 & 4.689 \\
\hline & EE-NOEC & 0.5320 & 0.4680 & L & 14.310 & 2.740 & 0.9819 & 0.0233 & 5.223 \\
\hline \multirow{4}{*}{$\mathrm{Zn}-\mathrm{Pb}$} & & $\mathrm{Zn}$ & $\mathrm{Pb}$ & & & & & & \\
\hline & EE-20 & 0.1970 & 0.8030 & $\mathrm{~L}$ & 11.910 & 2.530 & 0.9828 & 0.0314 & 4.706 \\
\hline & EE-50 & 0.2454 & 0.7546 & $\mathrm{~L}$ & 11.570 & 2.690 & 0.9852 & 0.0319 & 4.301 \\
\hline & EE-NOEC & 0.3940 & 0.6060 & $\mathrm{~L}$ & 13.800 & 2.550 & 0.9942 & 0.0182 & 5.412 \\
\hline
\end{tabular}



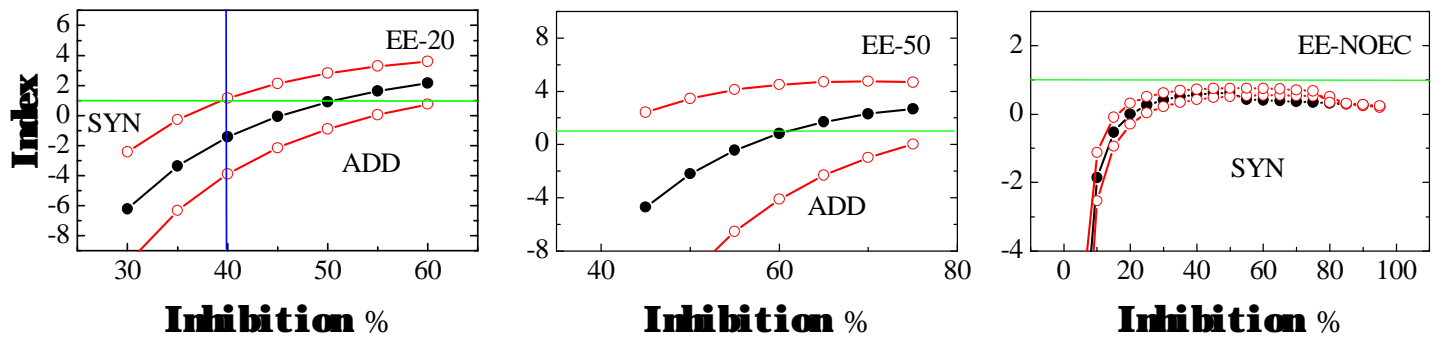

Fig. 2 The 96h response-Index curves of $\mathrm{Pb}-\mathrm{Cd}$ on S.obliquus.
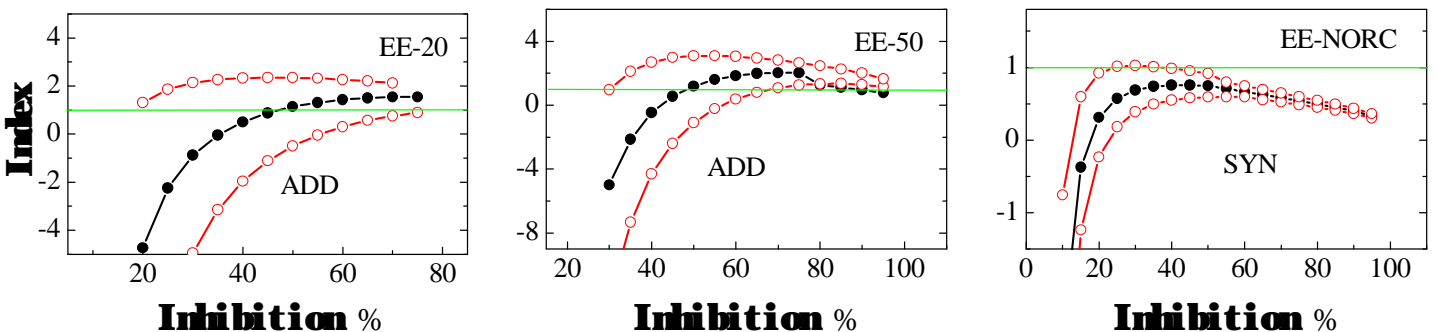

Fig.3 The 96h response-Index curves of $\mathrm{Zn}-\mathrm{Cd}$ on S.obliquus.
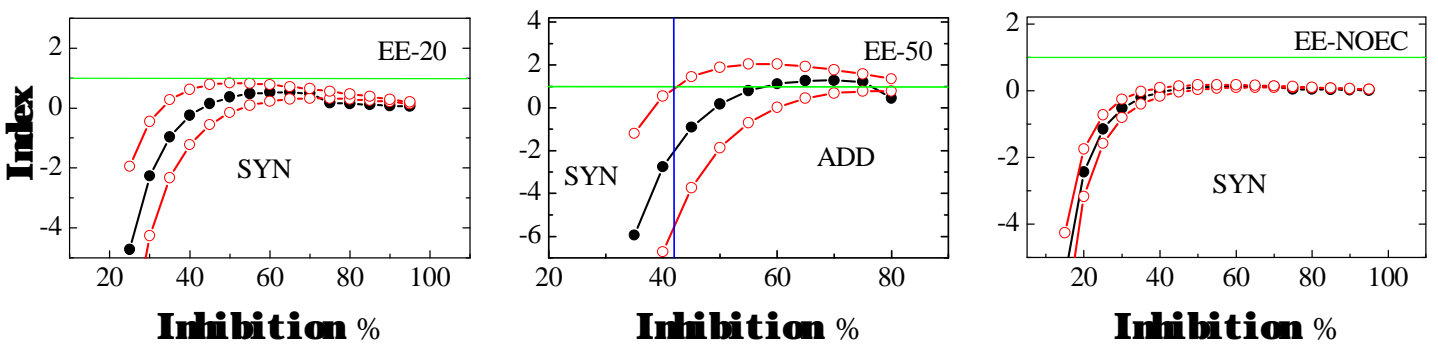

Fig.4 The 96h response-Index curves of $\mathrm{Zn}-\mathrm{Pb}$ on S.obliquus.

From the figure shows, for $\mathrm{Pb}-\mathrm{Cd}$ systems, EE-NOEC showed a synergistic effect, EE-20 showed synergistic effect in the range of 0-30 and the addition effect in the range of 30-100.EE-50 showed additive effect. For Zn-Cd system, EE-NOEC showed a synergistic effect, EE-20 and EE-50 showed additive effect. For Zn-Pb system, EE-NOEC and EE-20 showed a synergistic effect, EE-50 showed synergistic effect in the range of 0-40 and the addition in the range of 40-100.

\section{Conclusion}

The heavy metal for the study, the algae as biological experiments. The $96 \mathrm{~h}$ toxicity on S.obliquus were studied, the results showed that the toxicity of a single compound is: $\mathrm{Cd}>\mathrm{Zn}>\mathrm{Pb}$. Moreover, $\mathrm{Zn}-\mathrm{Pb}, \mathrm{Zn}-\mathrm{Cd}, \mathrm{Pb}-\mathrm{Cd}$ have interaction, Three systems of binary mixtures at low concentrations of the mixed region have shown a synergistic effect and at high concentration of the mixed performance of regional additive effect.

\section{Acknowledgements}

The authors are especially grateful to the financial support from the National Natural Science Fo-undation of China (21667013 and 21407032), the Provincial Natural Science Foundation of Guang-xi (2014GXNSFAA118060, 2014GXNSFBA118233), The project of high level innovation team an-d outstanding scholar in Guangxi colleges and universities (002401013001) and Guangxi Scientific Experiment Center of Mining, metallurgy and Environment. 


\section{References}

[1] WW Wenzel, R Unterbrunner, et al. Chelate-assisted phytoextraction using canola (Brassica napus L.) in outdoors pot and lysismeter experiments [J]. Plant Soil, 2003, 249 (1):83-96.

[2] M Rajkumar, MNV Prasad, et al. Biotechnological applications of serpentine bacteria for phytoremediation of heavy metals [J]. Critical Reviews in Biotechnology, 2009, 29(2): 120-130.

[3] Q Cai, ML Long, et al. Food chain transfer of cadmium an lead to cattle in a lead-zinc smelter in Guizhou[J], China. Environmental Pollution, 2009, 157(11): 3078-3082.

[4] E Dinc, F Onur. Comparative study of the ratio spectra derivative spectrophotometry, derivative spectrophotometry and Vierordt's applied to the analysis of lisinopril and hydrochlorthi - azide in tablets [J]. Spectrosc Lett, 1998, 31: 633-645.

[5] SS Liu, XQ Song, et al. Combined photobacterium toxicity of herbicide mixtures containing one insecticide [J]. Chemosphere, 2009, 75(3): 381-388.

[6] $\mathrm{X} \mathrm{Xu}, \mathrm{Y} \mathrm{Li}$, et al. Assessment of toxic interactions of heavy metals in multi-component mixtures using sea urchin embryo-larval bioassay [J]. Toxicology in Vitro, 2011, (1): 294-300.

[7] TC Chou. Derivation and properties of Michaelis-Menten type and Hill type equations for reference ligands [J]. Journal of Theoretical Biology, 1976, 59(2): 253-276. 